Article

\title{
Improved FAST Device for Inherent Safety of Oxide-Fueled Sodium-Cooled Fast Reactors
}

\author{
Ahmed Amin E. Abdelhameed ${ }^{1}$, Chihyung $\mathrm{Kim}^{2}$ and Yonghee Kim ${ }^{1, *}$ \\ 1 Korea Advanced Institute of Science and Technology (KAIST), Daejeon 34141, Korea; \\ aabdelhameed@anl.gov or ahmed.amin@kaist.ac.kr \\ 2 Korea Atomic Energy Research Institute (KAERI), Daejeon 34057, Korea; kch123@kaeri.re.kr \\ * Correspondence: yongheekim@kaist.ac.kr; Tel.: +82-42-350-3831; Fax: +82-42-350-3810
}

Citation: Abdelhameed, A.A.E.; Kim, C.; Kim, Y. Improved FAST Device for Inherent Safety of Oxide-Fueled

Sodium-Cooled Fast Reactors.

Energies 2021, 14, 4610. https:// doi.org/10.3390/en14154610

Academic Editor: Francesco Frusteri

Received: 27 May 2021

Accepted: 20 July 2021

Published: 29 July 2021

Publisher's Note: MDPI stays neutral with regard to jurisdictional claims in published maps and institutional affiliations.

Copyright: (c) 2021 by the authors. Licensee MDPI, Basel, Switzerland. This article is an open access article distributed under the terms and conditions of the Creative Commons Attribution (CC BY) license (https:/ / creativecommons.org/licenses/by/ $4.0 /)$.

\begin{abstract}
The floating absorber for safety at transient (FAST) was proposed as a solution for the positive coolant temperature coefficient in sodium-cooled fast reactors (SFRs). It is designed to insert negative reactivity in the case of coolant temperature rise or coolant voiding in an inherently passive way. The use of the original FAST design showed effectiveness in protecting the reactor core during some anticipated transients without scram (ATWS) events. However, oscillation behaviors of power due to refloating of the absorber module in FAST were observed during other ATWS events. In this paper, we propose an improved FAST device (iFAST), in which a constraint is imposed on the sinking (insertion) limit of the absorber module in FAST. This provides a simple and effective solution to the power oscillation problem. Here, we focus on an oxide fuel-loaded SFR that is characterized by a more negative Doppler reactivity coefficient and higher operating temperature than the metallicloaded SFR cores. The study is carried out for the $1000 \mathrm{MWth}$ advanced burner reactor with an oxide fuel-loaded core during postulated ATWS events that are unprotected transient over power, unprotected loss of flow, and unprotected loss of the heat sink. It was found that the iFAST device has promising potentials for protecting the oxide SFR core during the various studied ATWS events.
\end{abstract}

Keywords: sodium-cooled fast reactors; inherent safety; anticipated transients without scram; coolant temperature coefficient

\section{Introduction}

In fast neutron spectrum reactors, the fission-to-capture ratio usually increases with spectrum hardening. This is largely because the fission cross-section of actinides, including $\mathrm{Pu}$-239, changes just a little, while their capture cross-section sharply decreases with increasing neutron energy in the fast-spectrum region. As a result, the number of neutrons produced per neutron absorbed $(\eta)$ for $\mathrm{Pu}-239$ increases with spectrum hardening in fastspectrum reactors. This leads to more excess neutrons available for breeding fissile isotopes and transmutation of spent nuclear fuel in fast reactors. In addition, the high fission-tocapture ratio in a fast neutron spectrum leads to less generation of higher actinides, which simplifies fuel recycling. There are several fast spectrum reactor technologies that have been investigated for decades, such as lead cooled fast reactors (LFRs), and sodium-cooled fast reactors (SFRs). The SFRs can operate at a higher power density than LFRs. However, there are safety concerns of Na-water interactions which require utilizing an intermediate heat exchanger in SFRs [1,2]. In addition, the Na temperature increase will yield a hardened neutron spectrum, less Na capture, and enhanced leakage. Furthermore, in a low leakage SFR design, coolant void reactivity (CVR) and CTC can be clearly positive at burned core conditions [3].

In SFRs, the Doppler reactivity coefficient is more negative in an oxide fuel-loaded core (OLC) than that in a metallic fuel-loaded core (MLC). This is because the neutron spectrum is harder in a MLC. In addition, the oxide fuel has a lower thermal conductivity, and it operates at a higher temperature than a metallic fuel for the same power. The negative 
reactivity feedback from the axial fuel expansion is higher in a metallic fuel. However, in an MLC, the effects of the smaller fuel temperature and a smaller Doppler reactivity coefficient lead to lower asymptotic temperatures after anticipated transients without scram (ATWS) than those in an OLC. Therefore, it is necessary to improve the safety of oxide fuel-loaded SFRs.

Previously, a study was performed for FAST (floating absorber for safety at transient) as a solution for the positive CTC in SFRs [4]. The study was performed on the movement of the floating absorber module during the ATWS. The results showed promising potentials; however, oscillation behaviors of power and temperature due to refloating of FAST were observed during unprotected transient over power (UTOP) that may lead to core damage.

In this work, an improved FAST device (iFAST) design is suggested to minimize the oscillation of power and temperatures during the various ATWS events. Here, we describe the suggested design of the iFAST device with a constrained insertion limit of the absorber module. The study is carried out for the $1000 \mathrm{MWth}$ advanced burner reactor (ABR) with an oxide fuel-loaded core. The iFAST is designed to be installed in the ABR core by replacing a number of the fuel pins in the fuel assembly. In the numerical models, the power variation is calculated using the point kinetics equation with six delayed neutrons groups. The net reactivity of Doppler, coolant, radial core expansion, and axial fuel expansion reactivity feedback was considered, as well as the passive reactivity feedback from the iFAST device. The models also solve 1-D time-dependent balance equations in the axial direction and Navier-Stokes equation in the cylindrical direction to calculate the movement of the absorber module in the device. The studied ATWS scenarios are UTOP, unprotected loss of flow (ULOF), and unprotected loss of heat sink (ULOHS). Sensitivity analyses on the insertion limit in the iFAST device were carried out to find an optimum insertion limit for the ABR core. Furthermore, to demonstrate the effectiveness of the improved FAST device in protecting various SFR cores with no concern of power oscillation, two severe UTOP scenarios were studied, and the impact of varying the total worth of iFAST was investigated.

\section{Improved FAST Design}

The improved FAST device is designed to insert negative reactivity in the case of coolant temperature rise or coolant voiding in an inherently passive way. The density of the absorber and the volume of the void canister are determined to make the absorber module float above the core during normal operation. If the coolant temperature rises, the coolant density decreases. Thus, the absorber module in the iFAST pin sinks due to weakened buoyancy.

For the original design of the device [4,5], the oscillation of the power may lead to core failure, especially during UTOP. In order to solve this problem, the iFAST pin imposes a constraint on the insertion region of the absorber module, as demonstrated in Figure 1. The location of the constraint, or the insertion limit, in the iFAST pin, is optimized to minimize the power oscillation that is caused by the refloating of the absorber module. This represents a simple and effective improvement of the performance of the device during the various ATWS events.

The iFAST device has the same dimensions as the fuel pins, and it can be easily installed in conventional SFRs by replacing some fuel pins. Compared to other passivesafety devices, such as GEM (gas expansion module) [6] and ARC (autonomous reactivity control) [7], iFAST is unique because it can improve the CTC in an extremely simple way, and it is applicable without changes in the fuel assembly design. This study is mainly dedicated to demonstrating the effectiveness of the iFAST device in protecting the core of a large-size oxide SFR during UTOP, ULOHS, and ULOF. The iFAST design for ABR is $0.3775 \mathrm{~cm}$ in radius, and the radius of the absorber module in the device is $0.2 \mathrm{~cm}$. The absorber module height is $80 \mathrm{~cm}$ which includes $60 \mathrm{~cm}$ for the absorber module and $20 \mathrm{~cm}$ for the void canister, and it is designed so that the average density of the absorber module is $0.832 \mathrm{~g} / \mathrm{cm}^{3}$. 


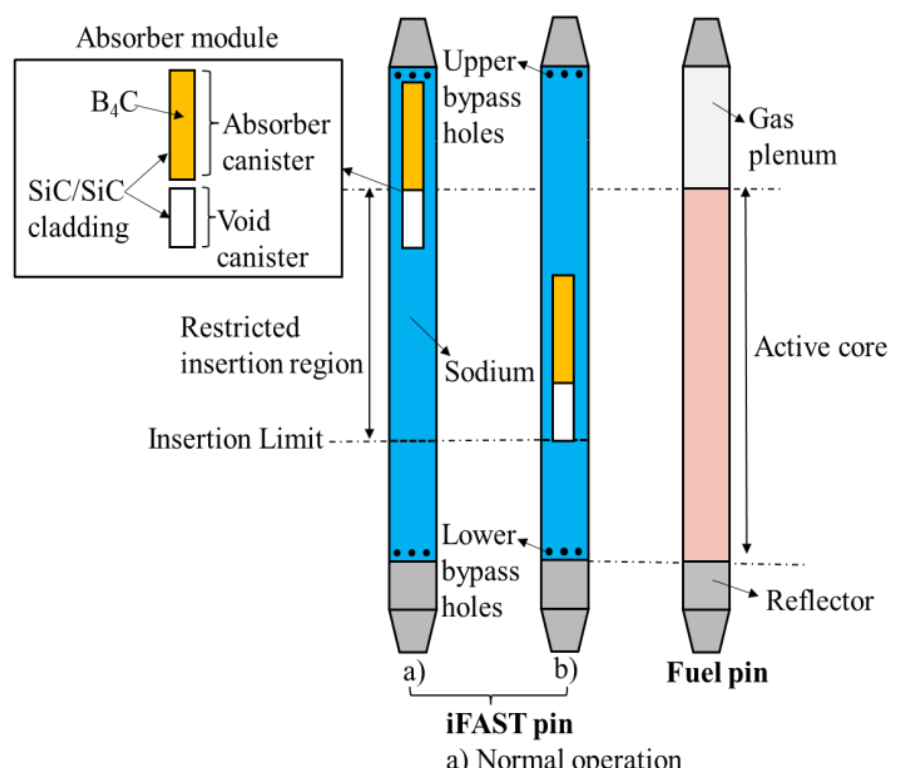

a) Normal operation

b) ATWS

Figure 1. Concept of the iFAST device.

\section{Methods and Assumptions for Evaluation of iFAST}

The algorithm of the models used in this work is demonstrated in Figure 2. The point kinetics equation (PKE) with six delayed neutrons groups is used to determine the power variation, as shown in Equation (1). Meanwhile, Equation (2) is used to update the net reactivity that is the summation of the initial reactivity, Doppler reactivity feedback, coolant reactivity feedback, radial core expansion reactivity feedback, axial fuel expansion reactivity feedback, excess reactivity, and iFAST reactivity feedback. It should be noticed that reactivity feedback from iFAST is a sort of external reactivity feedback that is inserted in an inherently passive manner due to the coolant temperature variation.

$$
\begin{gathered}
\dot{p}(t)=\frac{\rho(t)-\beta}{\Lambda} p(t)+\sum_{k} \lambda_{k} C_{k}(t), \\
\dot{C}_{k}(t)=\frac{\beta_{k}}{\Lambda} n(t)-\lambda_{k} C_{k}(t) . \\
\rho(t)=\rho_{0}+\alpha_{\text {fuel }} \Delta T_{\text {fuel }}+\alpha_{\text {coolant }} \Delta T_{\text {coolant }}+\alpha_{\text {radial expansion }} \Delta T_{\text {coolant }}+\alpha_{\text {axial expansion }} \Delta T_{\text {fuel }}+\Delta \rho_{\text {ex }}+\Delta \rho_{\text {FAST }} .
\end{gathered}
$$

The 1000 MWth ABR core developed by Argonne National Laboratory [8,9] is chosen as an oxide fuel-loaded reference core for the analysis of iFAST behavior during the ATWS events. The kinetic parameters and reactivity feedback coefficients of ABR at EOL are listed in Tables 1 and 2. Figure 3 shows the axial temperature distribution in the $1.067 \mathrm{~m}$ long active core region of $A B R$ calculated by an in-house thermal-hydraulics code. It should be noted that chopped cosine-shaped axial power distribution is assumed, and 1-D time-dependent energy and mass conservations are considered in the axial direction. The velocity field of the coolant surrounding the absorber module in iFAST is calculated using the Navier-Stokes equation in a cylindrical shape $[4,10]$. Based on the calculated velocity, the position of the absorber module is calculated. The position-wise reactivity worth of the absorber module in iFAST is shown in Figure 4, which is utilized to determine the iFAST reactivity feedback. 


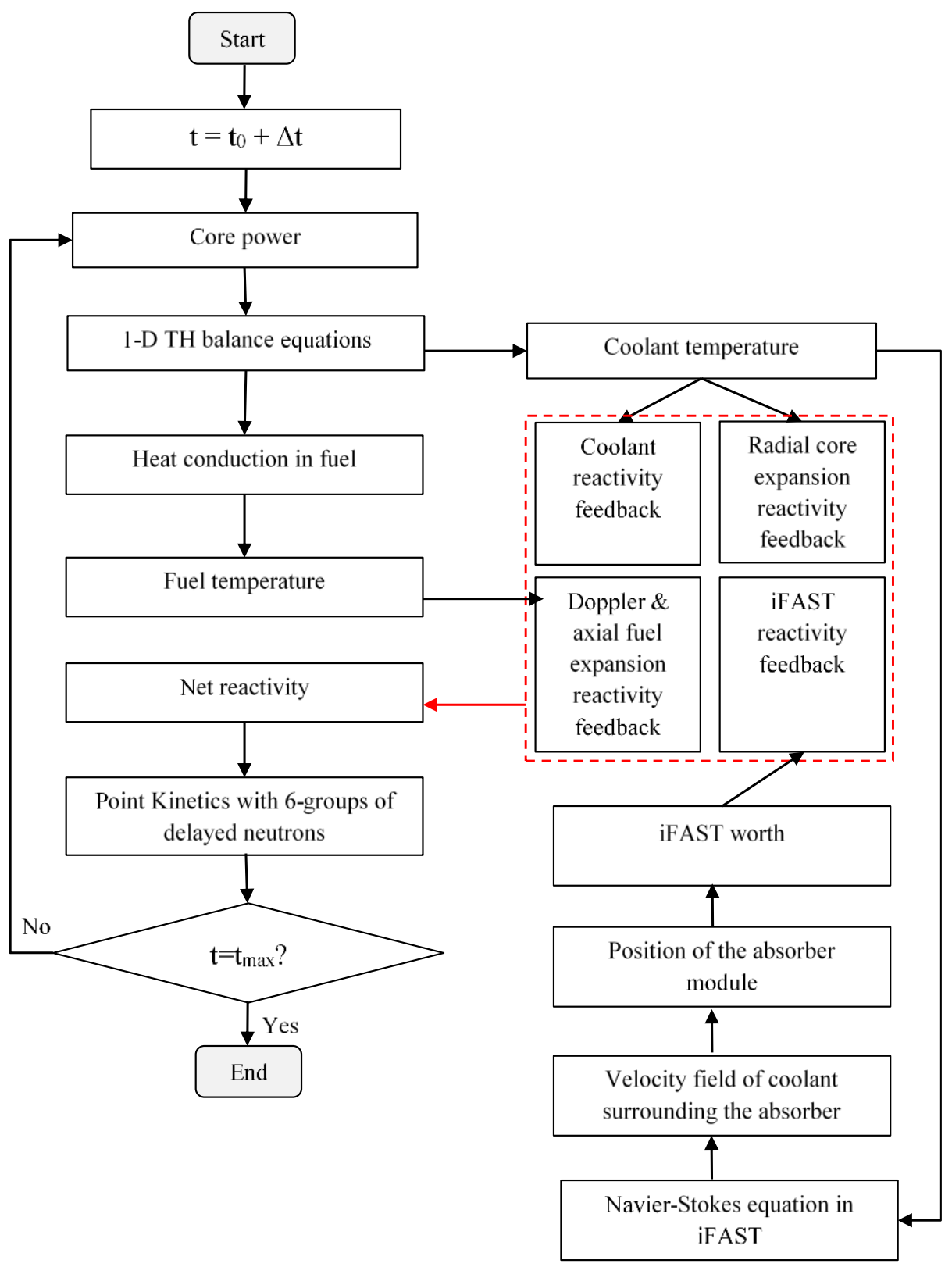

Figure 2. Algorithm of system modeling, including movement of the absorber module in iFAST.

Table 1. Kinetic parameters of the large-size oxide SFR ABR.

\begin{tabular}{ccc}
\hline & Kinetic Parameters (EOL) & \\
\hline $\mathbf{G}$ & $\boldsymbol{\beta g}$ & $\boldsymbol{\lambda} \mathbf{g}$ \\
\hline 1 & $5.36 \times 10^{-5}$ & 0.0124 \\
\hline 2 & $5.73 \times 10^{-4}$ & 0.0305 \\
\hline 3 & $5.08 \times 10^{-4}$ & 0.111 \\
\hline 4 & $1.31 \times 10^{-3}$ & 0.301 \\
\hline 5 & $5.22 \times 10^{-4}$ & 1.14 \\
\hline 6 & $1.33 \times 10^{-4}$ & 3.01 \\
\hline
\end{tabular}


Table 2. Reactivity feedback coefficients of the large-size oxide SFR ABR.

\begin{tabular}{cc}
\hline \multicolumn{2}{c}{ Reactivity Feedback Coefficients (EOL) } \\
\hline Parameters & Value \\
\hline Fuel temperature $(\mathrm{pcm} / \mathrm{K})$ & -0.372 \\
\hline Coolant temperature $(\mathrm{pcm} / \mathrm{K})$ & 0.496 \\
\hline Axial expansion $(\mathrm{pcm} / \mathrm{K})$ & -0.155 \\
\hline Radial expansion $(\mathrm{pcm} / \mathrm{K})$ & -0.930 \\
\hline Effective delayed neutron fraction & 0.0031 \\
\hline Prompt neutron lifetime $(\mu \mathrm{s})$ & 0.420
\end{tabular}

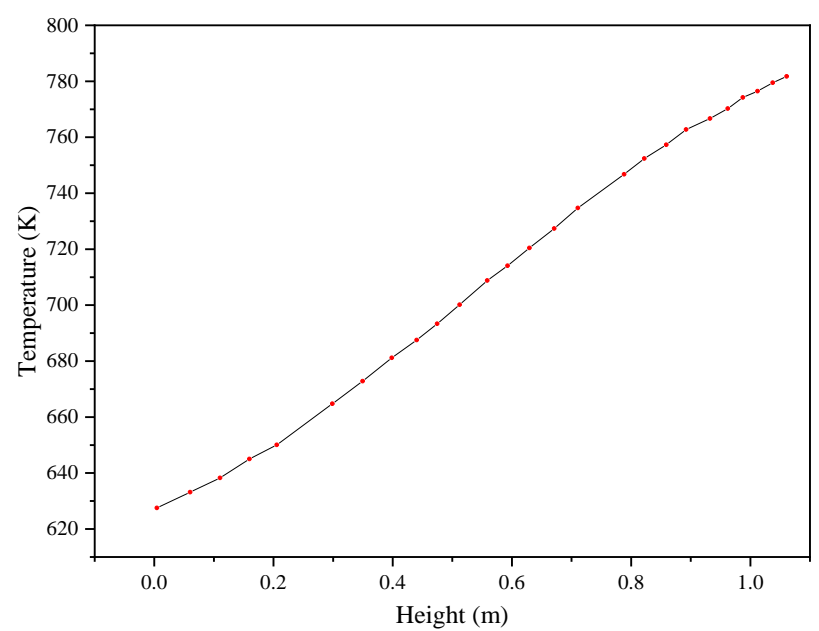

Figure 3. Coolant temperature rise.

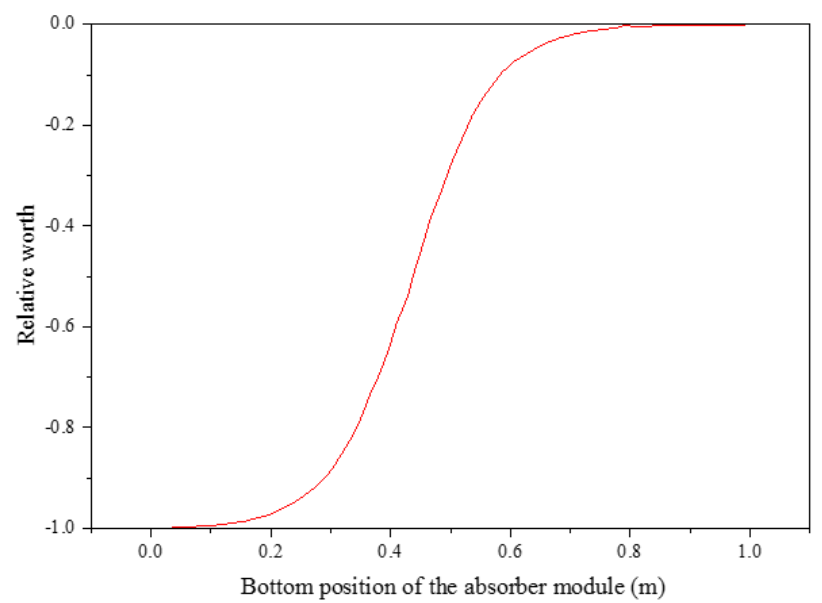

Figure 4. Position-wise relative reactivity worth of the absorber module.

\section{Results and Discussion}

The utilization of the iFAST device in the oxide fuel-loaded core aims to enhance the passive negative reactivity feedback in response to any ATWS events. This is important to rapidly shut down and protect the reactor core. The insertion of the absorber module in the iFAST device due to coolant temperature increase introduces an inherently passive negative reactivity feedback that helps in mitigating the hazardous consequences of the ATWS events in oxide-loaded SFRs. 


\subsection{Unprotected Loss of Flow in ABR}

In the simulated ULOF, we assumed failure of all the coolant pumps in the primary system. Consequently, the coolant mass flow rate quickly decreases, and we assumed a pump halving time of $5 \mathrm{~s}$ and $5 \%$ natural circulation. Meanwhile, the inlet coolant temperature remains unchanged during the simulation. An in-house code based on the Fortran-90 program was used to solve the numerical models demonstrated in Figure 2. The study was carried out with and without utilizing the iFAST device to demonstrate its effectiveness in reducing the maximum coolant and fuel temperatures during the ULOF. Here, we compared the results for two assumed maximum worth of iFAST that are $1.8 \$$ and $1 \$$.

In addition, a sensitivity study on the insertion limit was made to study its impact on avoiding large oscillation of the reactor power due to an unfavorable, big refloating of the absorber module in iFAST. The insertion limit was measured from the bottom of the active core region. Thus, for example, a $0.1 \mathrm{~m}$ insertion limit means a deeper insertion limit than $0.2 \mathrm{~m}$. It should be noticed that the numerical simulations were stopped if the coolant temperature reaches its boiling temperature, which is $1156 \mathrm{~K}$ because only a single-phase flow is considered in the current models.

Figure 5 demonstrates the numerical results of ULOF for $1.8 \$$ maximum iFAST worth. In Figure 5, the reactor power, the movement of the absorber module in iFAST, and the maximum coolant and fuel temperatures during the ULOF are plotted. The reactor power decreased due to the net negative reactivity feedback even without utilizing the iFAST device. However, utilizing iFAST yielded a faster power ramping-down rate. The decrease of coolant flow rate initially led to a rise in core coolant temperature. Thus, the absorber module in the iFAST pin sinks due to the weakened buoyancy force. This introduced negative reactivity feedback, which enhanced the power ramping-down rate. In addition, a deeper insertion limit, i.e., $0.1 \mathrm{~m}$, yielded faster power ramping-down rate during the ULOF. Nevertheless, the insertion limit in iFAST must be optimized in view of the reactor safety during the various ATWS, especially because oscillations of the reactor power were previously reported for the UTOP scenario with the old FAST design without an optimized insertion limit (insertion limit $=0$ ). Figure $5 \mathrm{~b}$ shows the movement of the absorber module in the iFAST device after the ULOF. The refloating of the absorber module is bigger for a deeper insertion limit, however, without causing any hazardous consequences or any oscillation of the reactor power. Figure $5 \mathrm{c}$ shows that the maximum coolant temperature initially increased due to the decrease of the flow rate. Then the temperature decreases due to the decline in the reactor power. The iFAST noticeably reduced the maximum coolant temperature due to the faster power decrease. Furthermore, the maximum fuel temperature was also significantly reduced by utilizing the iFAST device, as shown in Figure 5d. In addition, the deeper insertion limit in iFAST yielded lower asymptotic maximum coolant and fuel temperatures. It is clear from Figure 5 that without utilizing iFAST and with an insertion limit of $0.5 \mathrm{~m}$, the maximum boiling temperature exceeds the boiling temperature. However, the maximum coolant and fuel temperatures remain below the failure limits for $0.1,0.2$, and $0.3 \mathrm{~m}$ insertion limits.

Figure 6 demonstrates the numerical results of ULOF for $1 \$$ maximum iFAST worth. Due to the smaller iFAST worth, the maximum coolant temperature can be sufficiently below the boiling temperature only for a $0.1 \mathrm{~m}$ insertion limit or deeper. Figure 7 demonstrates the variation of the reactivity components during the ULOF for $1 \$$ iFAST worth. The reactivity components shown in Figure 7 are the Doppler reactivity feedback, the expansion feedback from both radial core expansion and axial fuel expansion, the coolant reactivity feedback, and the inherently passive reactivity feedback from the iFAST device. Figure 7 shows relatively strong negative reactivity feedback from iFAST in response to the ULOF without any external reactivity control. 


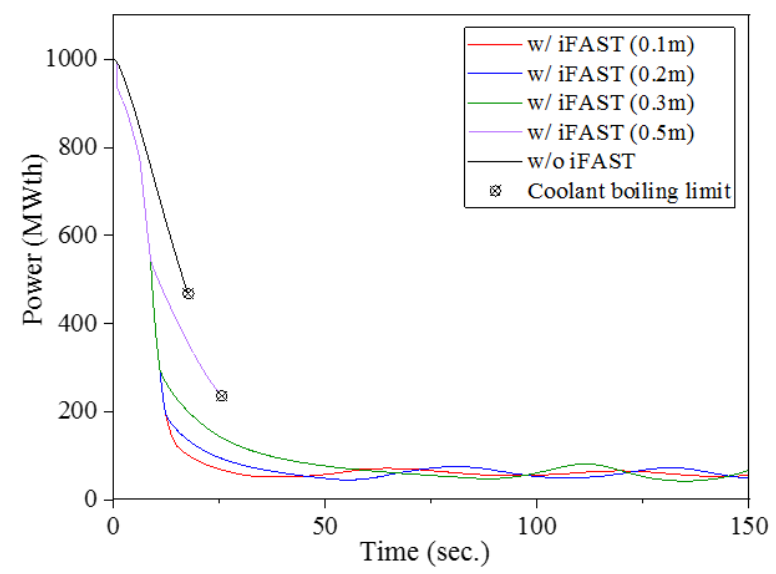

(a) Core power

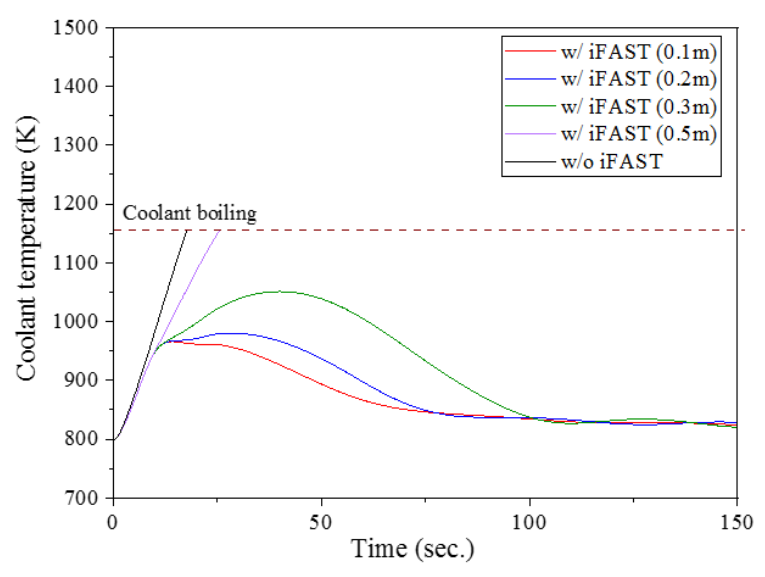

(c) Maximum coolant temperature

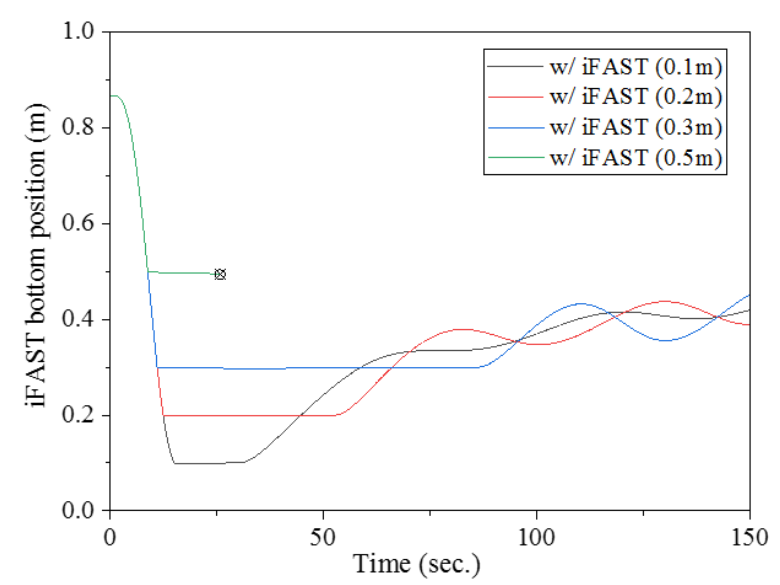

(b) Movement of the absorber module

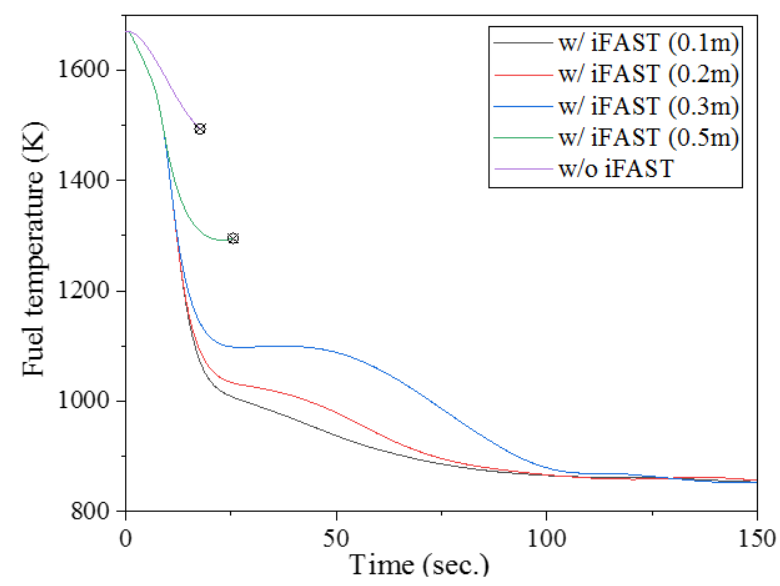

(d) Maximum fuel temperature

Figure 5. Unprotected loss of flow in ABR reactor and 1.8\$ maximum iFAST worth.

\subsection{Unprotected Transient Overpower in ABR}

A UTOP scenario in ABR is demonstrated in Figure 8. In this scenario, we assumed a $50 \mathrm{~s}$ of external reactivity insertion with a ramp rate of $0.008 \$ / \mathrm{s}(0.4 \$ / 50 \mathrm{~s})$ in the ABR core while keeping the nominal coolant flow rate. In the UTOP simulation shown in Figure 8 , $1.8 \$$ maximum worth of the iFAST and a constant temperature drop in the intermediate heat exchanger (IHX) are assumed. Figure 8 shows that the asymptotic maximum fuel and coolant temperatures were sufficiently reduced by utilizing the iFAST device.

Figure 8 shows that a deeper insertion limit below $0.6 \mathrm{~m}$ yields smaller maximum fuel and coolant temperatures. However, it also shows that there is no advantage for a deeper insertion limit below $0.5 \mathrm{~m}$. For $0.6 \mathrm{~m}$ insertion a very limited power oscillation is noticed. Larger power oscillations are noticed for $0.5 \mathrm{~m}$ and deeper insertion limits. However, these power oscillations are quickly dampened. A similar UTOP scenario, but with assuming constant inlet coolant temperature, is illustrated in Figure 9. It was found that the iFAST significantly reduces the maximum coolant and fuel temperatures, especially for $0.5 \mathrm{~m}$ or deeper insertion limits.

In a previous study on the original FAST device [4], the continuous oscillation of power and temperatures were noticed for more severe UTOP (1\$/50 s) and 1\$ worth of the device. To demonstrate the impact of optimizing the insertion limit in removing such oscillations, we performed sensitivity analysis on the insertion limit during the UTOP and $1 \$$ worth of the iFAST. Figure 10 shows $50 \mathrm{~s}$ of external reactivity insertion with a ramp rate of 0.02 \$/s in the ABR core. The nominal coolant flow rate and a constant temperature drop in the intermediate heat exchanger (IHX) and $1 \$$ maximum worth of iFAST were assumed. 


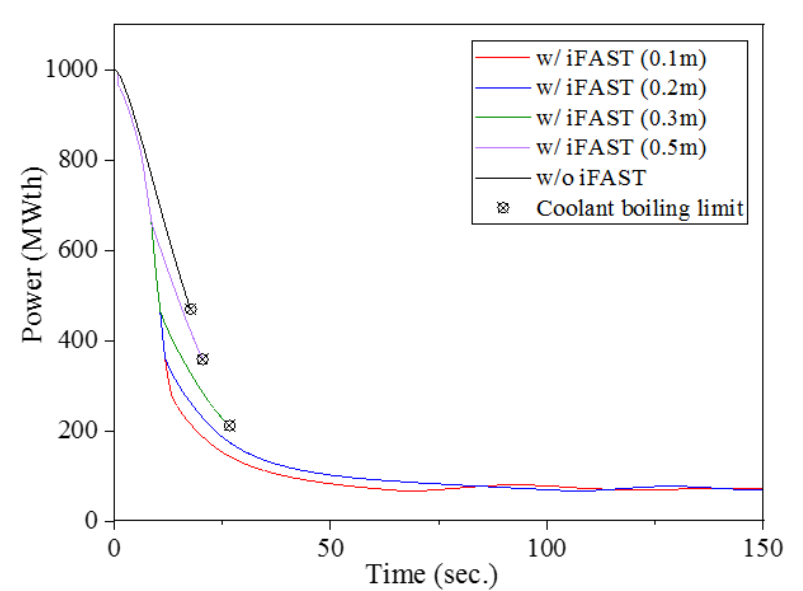

(a) Core power

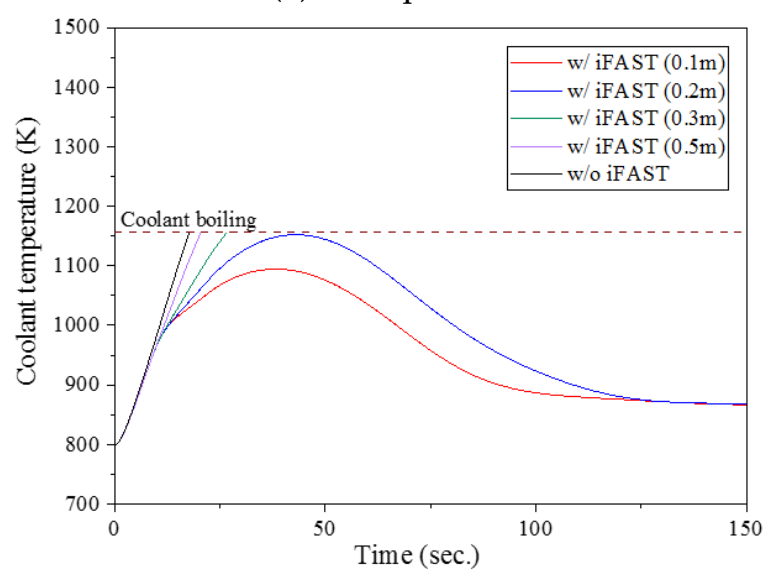

(c) Maximum coolant temperature

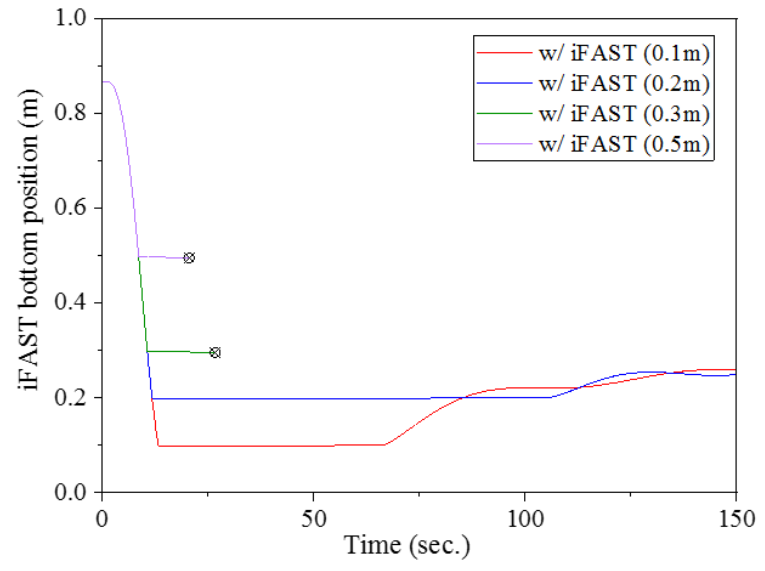

(b) Movement of the absorber module

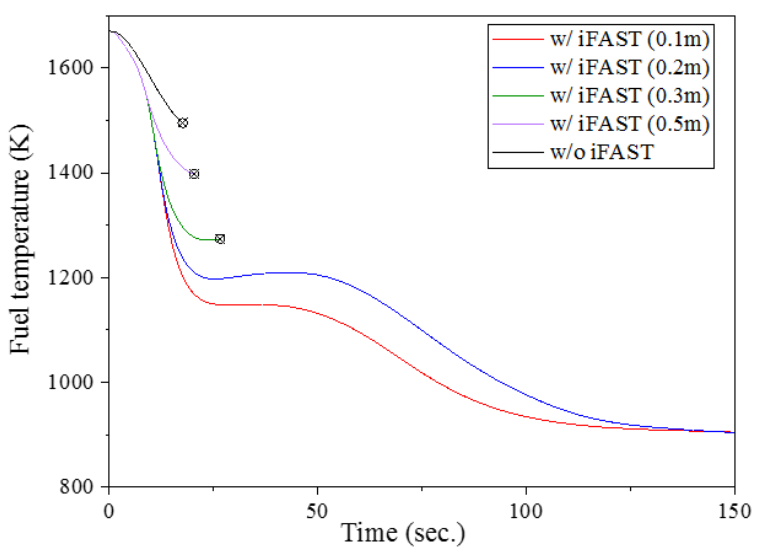

(d) Maximum fuel temperature

Figure 6. Unprotected loss of flow in ABR reactor and $1 \$$ maximum iFAST worth.

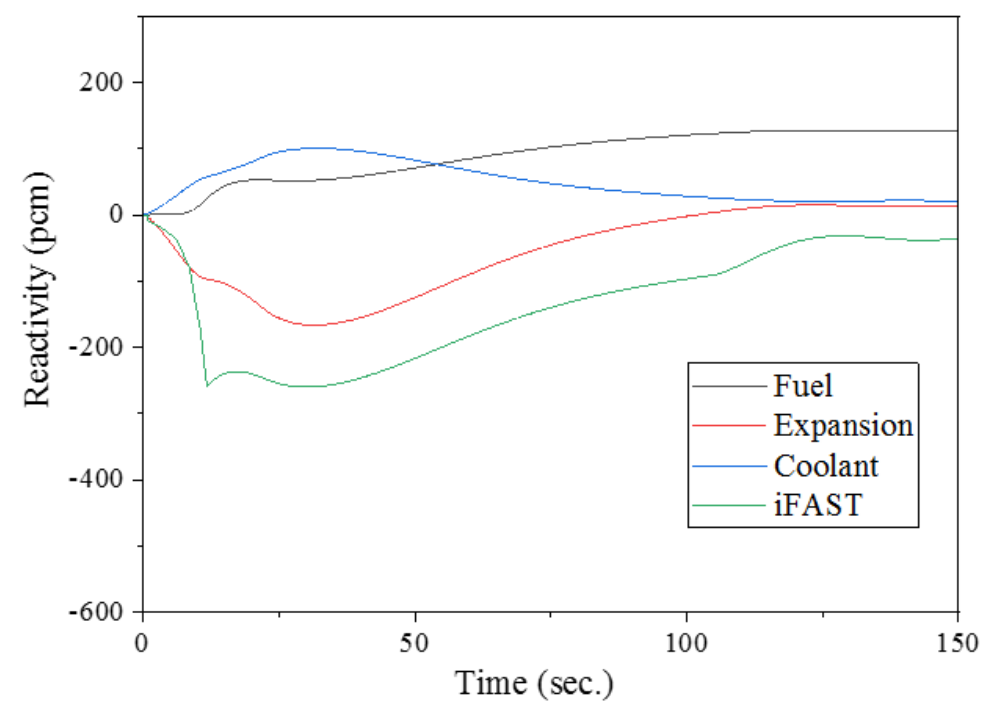

Figure 7. The variation of the reactivity components during ULOF for $1 \$$ maximum iFAST worth and $0.2 \mathrm{~m}$ insertion limit. 


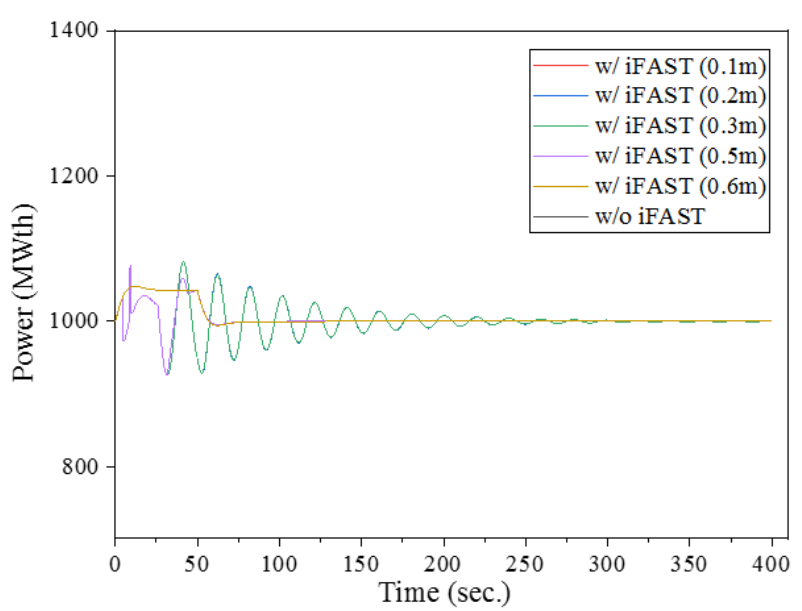

(a) Core power

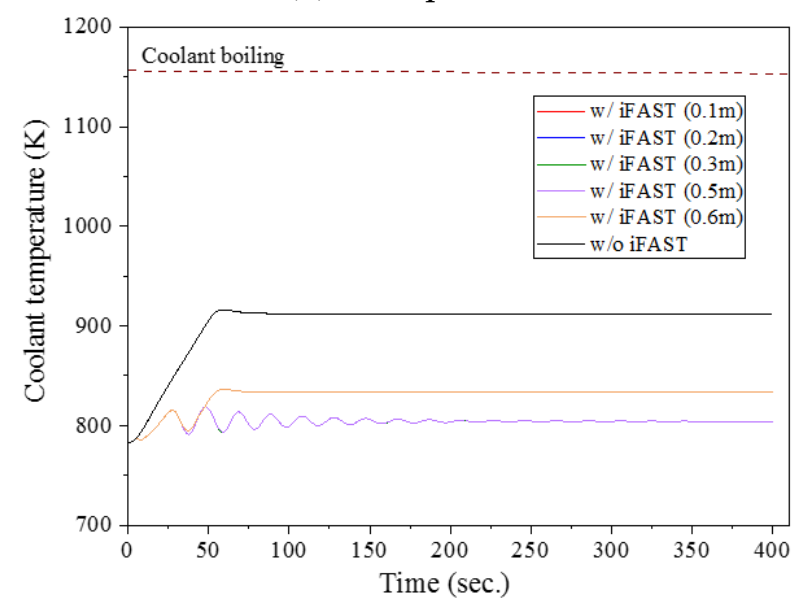

(c) Maximum coolant temperature

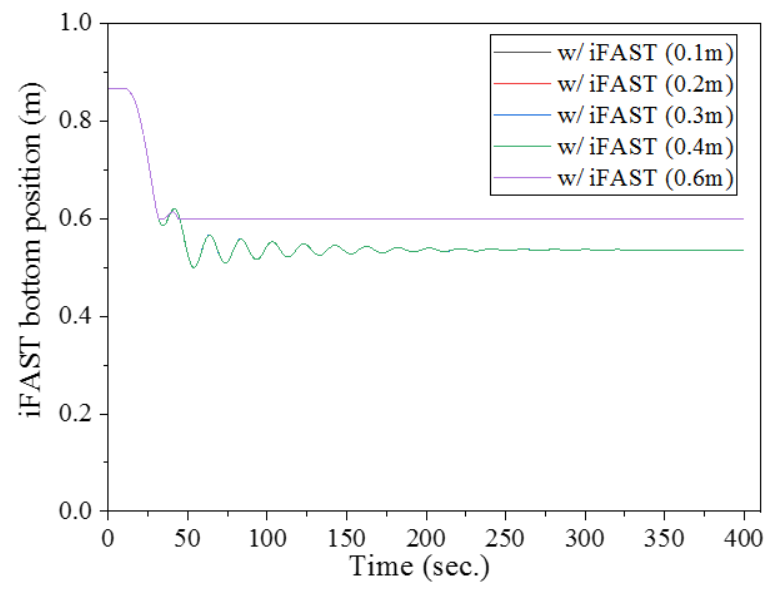

(b) Movement of the absorber module

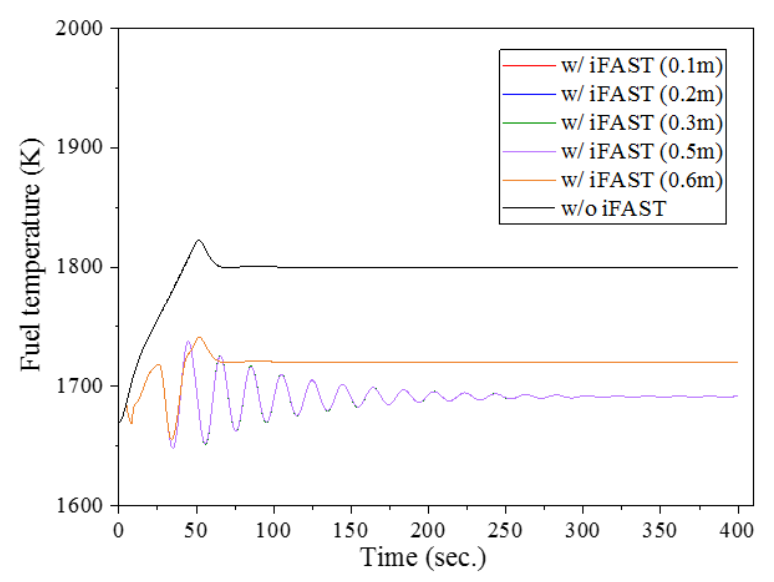

(d) Maximum fuel temperature

Figure 8. Unprotected transient over power $(0.4 \$ / 50 \mathrm{~s})$ with a constant temperature drop in IHX and $1.8 \$$ maximum iFAST worth.

The asymptotic maximum fuel and coolant temperatures were sufficiently reduced by utilizing the iFAST device. For insertion limits from 0.5 to $0.2 \mathrm{~m}$, a deeper insertion limit yielded smaller maximum fuel and coolant temperatures. Nevertheless, clear oscillations of power and coolant temperatures occurred for the $0.1 \mathrm{~m}$ insertion limit. This is because of the refloating of the absorber module in iFAST, as shown in Figure 10b. A simple solution to the power oscillation problem was to reduce the refloating/insertion region by optimizing the insertion limit in iFAST. The negative reactivity feedback from iFAST mitigates the consequences of the positive coolant reactivity feedback throughout the UTOP. For a $0.2 \mathrm{~m}$ insertion limit, the small refloating of the absorber module caused limited oscillation of the iFAST reactivity feedback and the reactor power. However, such a small refloating was quickly dampened, as shown in Figure 10a. Meanwhile, the least variation of maximum fuel and coolant temperatures occurred by using iFAST with a $0.2 \mathrm{~m}$ insertion limit, as illustrated in Figure 10c,d. Therefore, from the viewpoint of both reducing the core temperatures and preventing the power oscillation, utilizing iFAST, which has an insertion limit at $0.2 \mathrm{~m}$, was successful in preventing the core failure even in such a postulated severe UTOP scenario. 


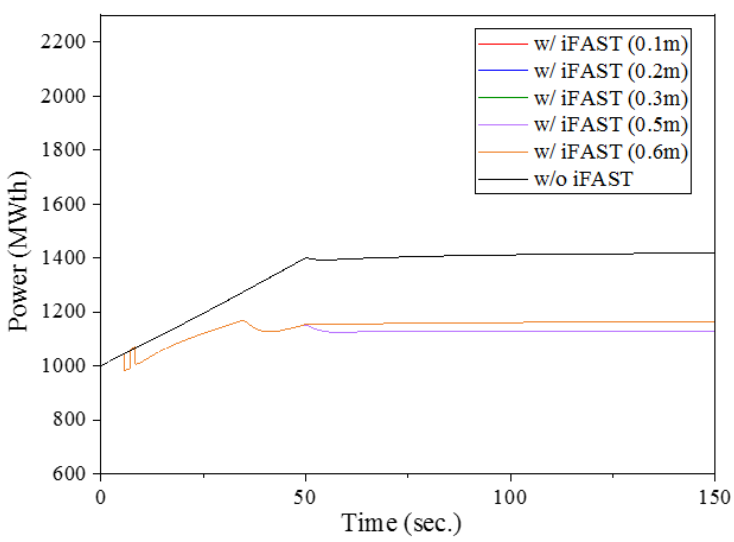

(a) Core power

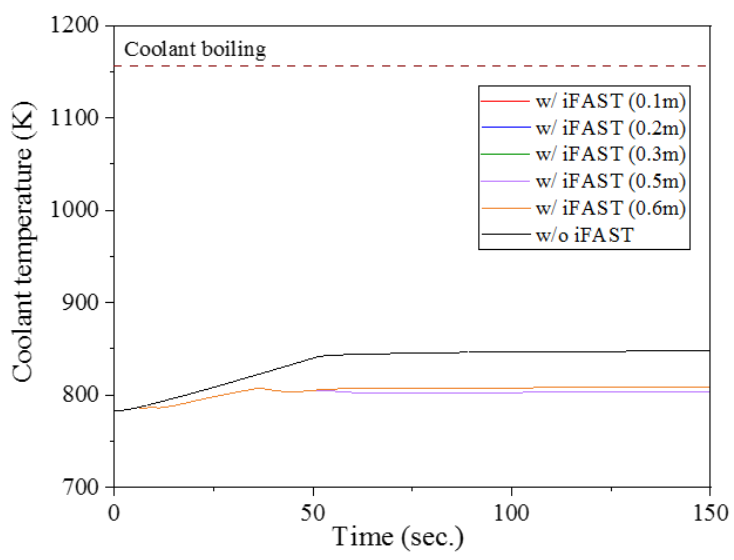

(c) Maximum coolant temperature

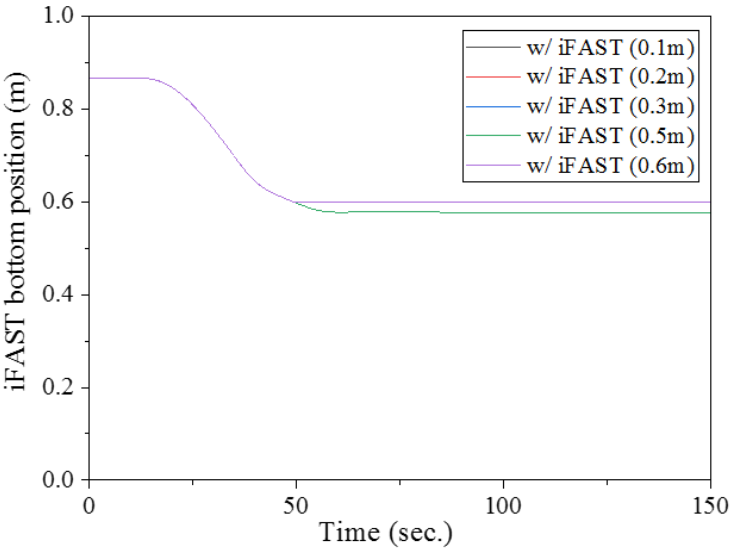

(b) Movement of the absorber module

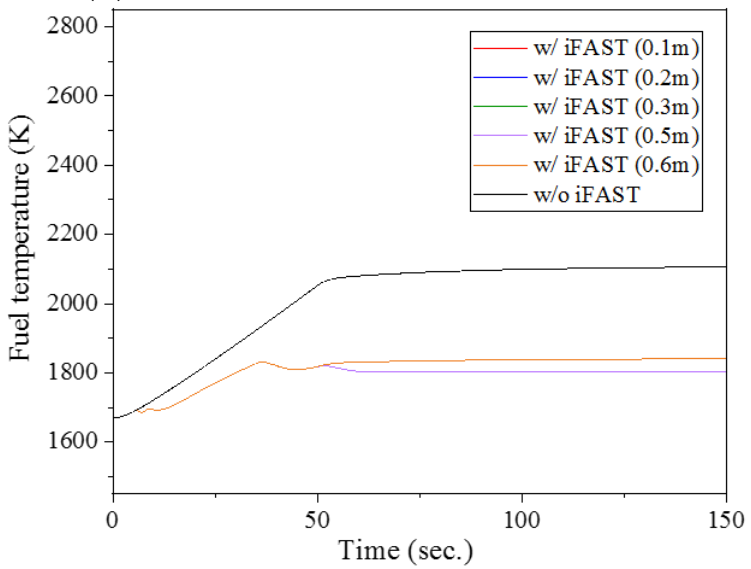

(d) Maximum fuel temperature

Figure 9. Unprotected transient over power $(0.4 \$ / 50 \mathrm{~s})$ with constant inlet temperature in IHX and $1.8 \$$ maximum iFAST worth.

Figure 11 demonstrates a similar severe UTOP scenario and iFAST worth but with a constant inlet coolant temperature. The reactor power was quickly doubled, and the maximum fuel temperature exceeded the failure limit, as shown in Figure 11. This indicates that that the oxide SFR core without a reactivity safety device will fail in such a severe UTOP scenario. Nevertheless, in the case of utilizing iFAST, due to the increase of coolant temperature, the absorber module in iFAST will sink and provide a relatively large negative reactivity feedback that limits the power increase. Figure 11a shows a significant reduction of the asymptotic power due to utilizing iFAST with a deep insertion limit. The movement of the absorber module is shown in Figure 11b. As a result, the maximum coolant fuel temperatures were effectively reduced, and the reactor core was protected, as illustrated in Figure $11 \mathrm{c}, \mathrm{d}$.

\subsection{Unprotected Loss of Heat Sink in ABR}

We also investigated a ULOHS scenario in the ABR core where we assumed a complete loss of the IHX over $20 \mathrm{~s}$ while the primary coolant flow rate remains unchanged. Figure 12 demonstrates the ULOHS in ABR with and without utilizing iFAST and 1.8\$ maximum iFAST worth. A sensitivity analysis of the insertion limit in iFAST was performed. Due to the net reactivity feedback, the reactor power eventually goes to zero, even without utilizing iFAST. Once again, the utilization of iFAST yielded a faster power decrease, as illustrated in Figure 11a. The movement of the absorber module is shown in Figure 11b. No refloating of the absorber module occurred for all the studied insertion limits in iFAST, and a deeper insertion limit resulted in a faster power decrease. For $1.8 \$$ maximum iFAST worth, the maximum coolant and fuel temperatures during the ULOHS are below the failure limit, as designed for $0.2 \mathrm{~m}$ or deeper, as shown in Figure 11c,d. However, for $1 \$$ 
maximum iFAST worth, the maximum coolant temperature reaches the boiling limit even for a $0.1 \mathrm{~m}$ insertion limit, as shown in Figure 13.

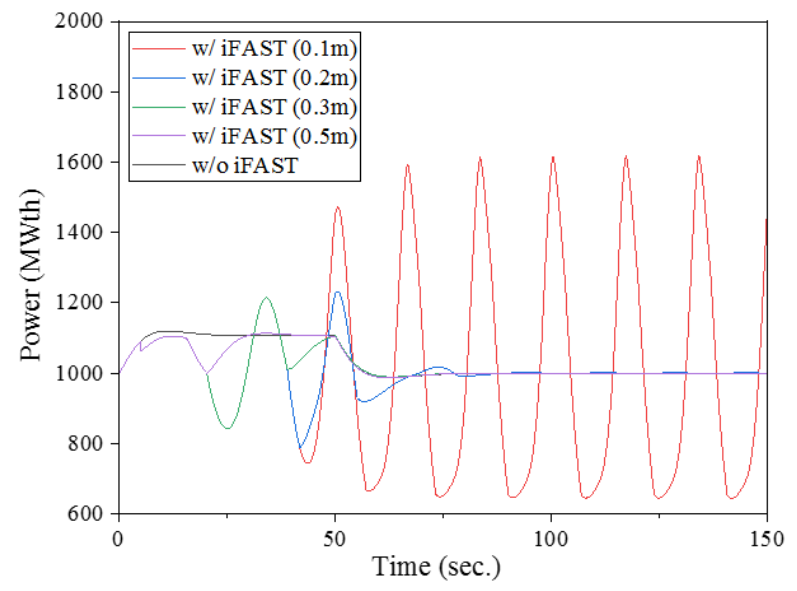

(a) Core power

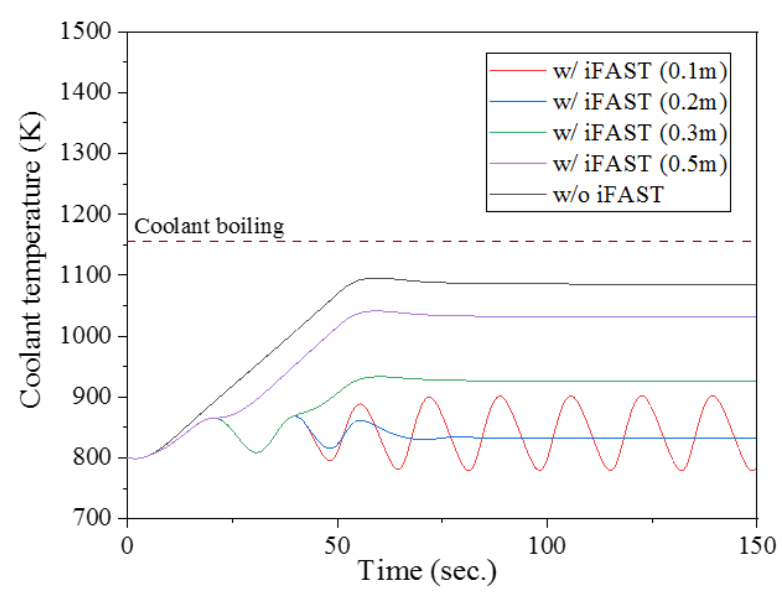

(c) Maximum coolant temperature

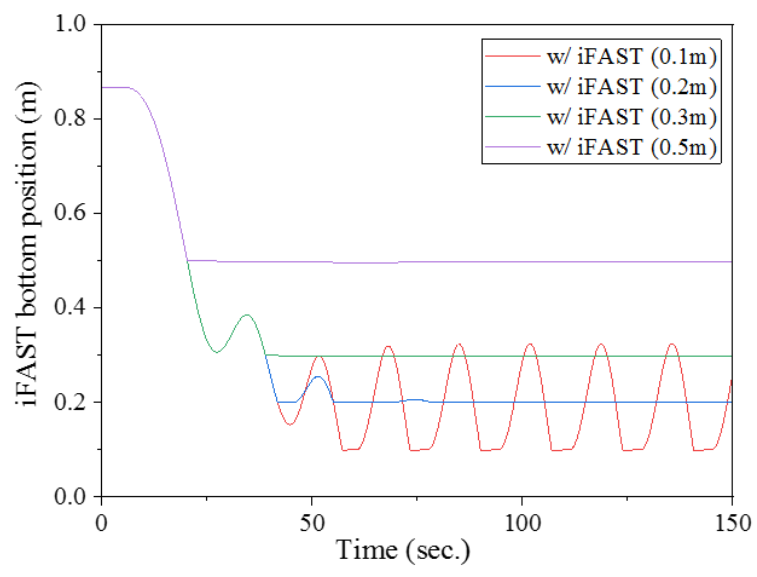

(b) Movement of the absorber module

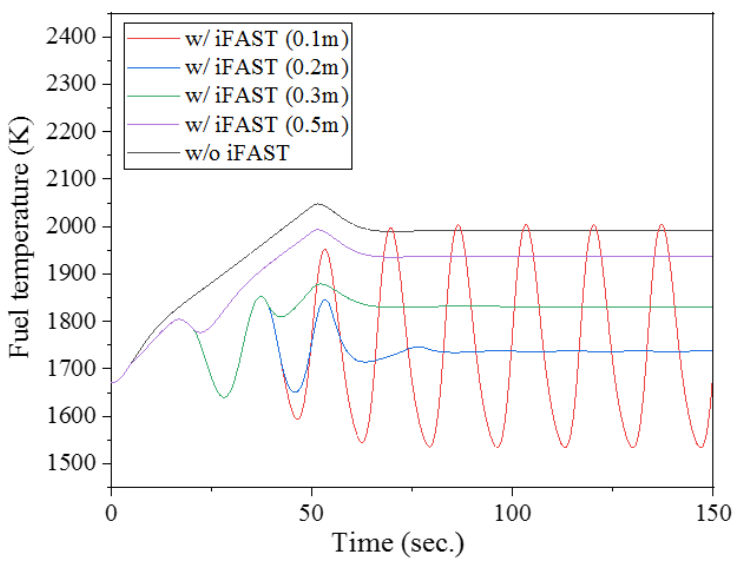

(d) Maximum fuel temperature

Figure 10. Unprotected transient over power $(1 \$ / 50 \mathrm{~s})$ with constant temperature drop in IHX and $1 \$$ maximum iFAST worth.

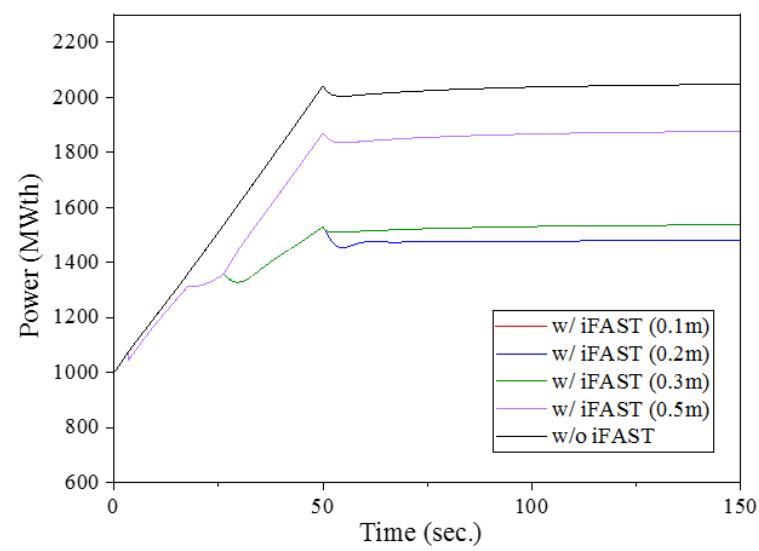

(a) Core power

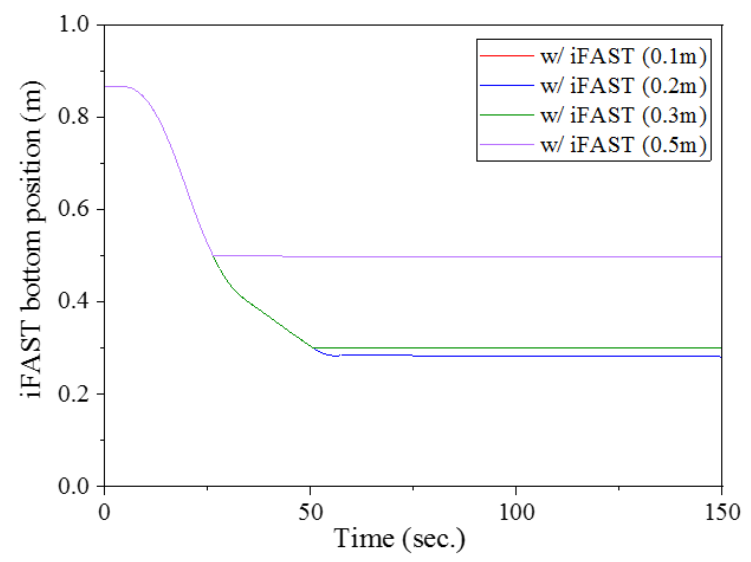

(b) Movement of the absorber module

Figure 11. Cont. 


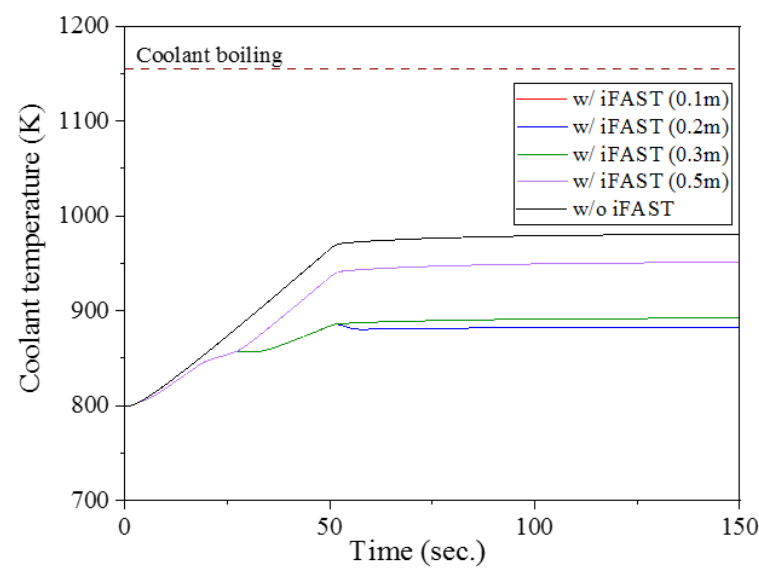

(c) Maximum coolant temperature

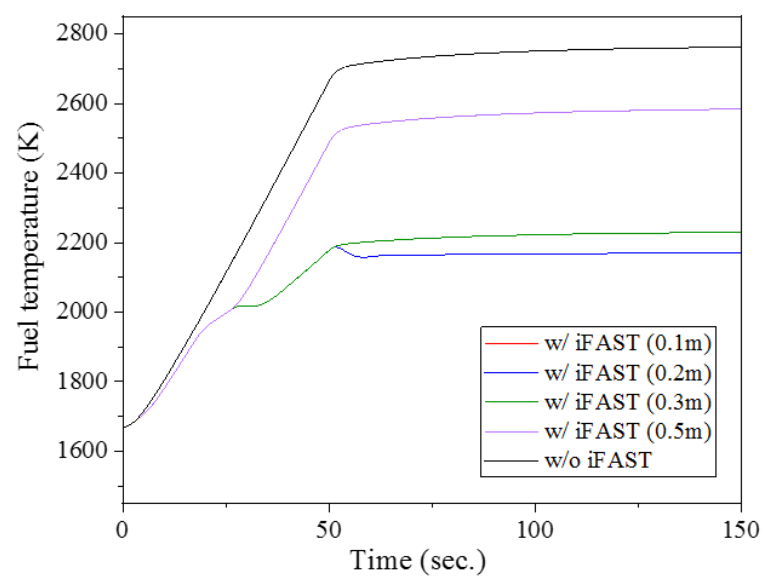

(d) Maximum fuel temperature

Figure 11. Unprotected transient over power $(1 \$ / 50 \mathrm{~s})$ with constant inlet temperature and $1 \$$ maximum iFAST worth.

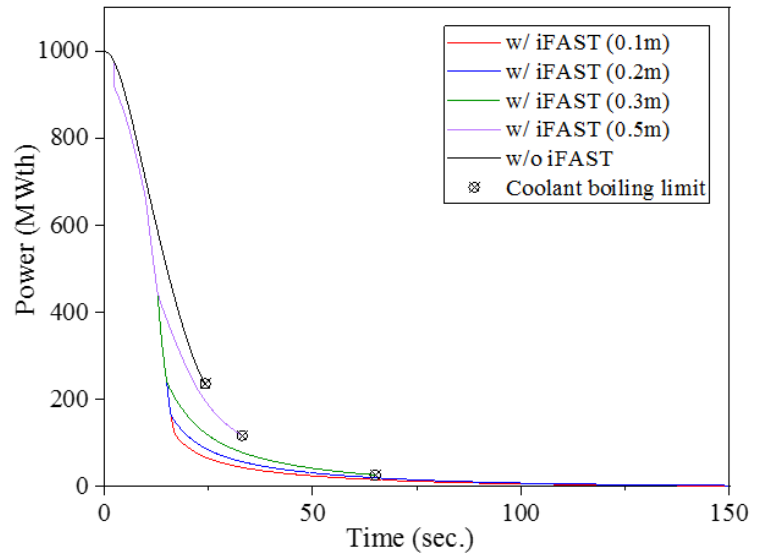

(a) Core power

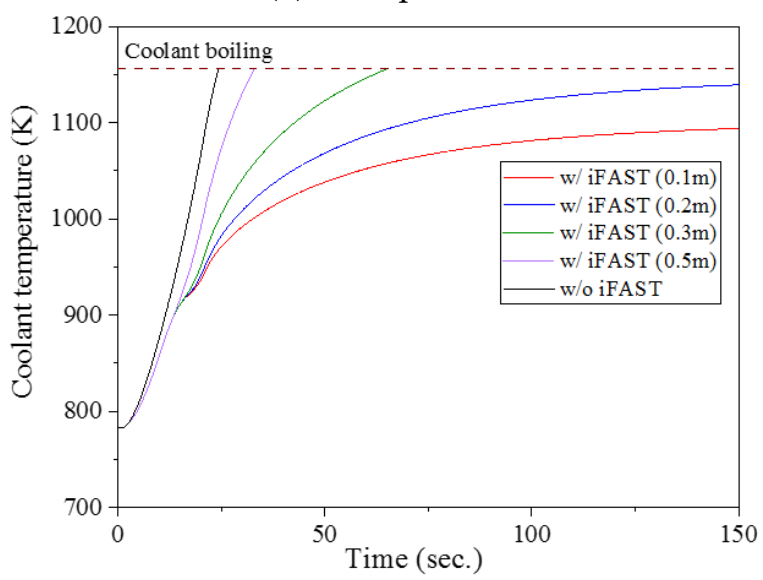

(c) Maximum coolant temperature

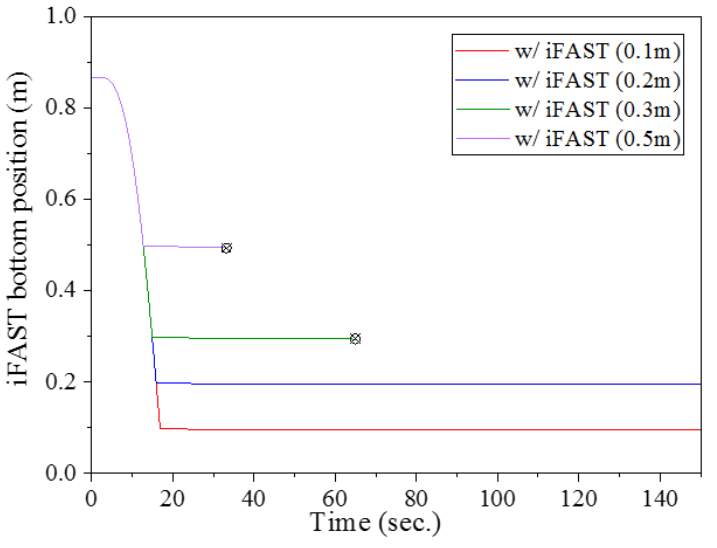

(b) Movement of the absorber module

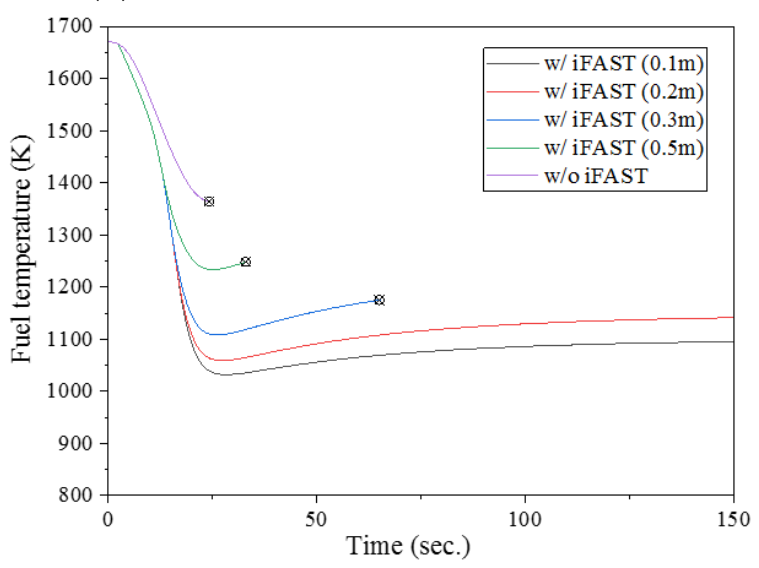

(d) Maximum fuel temperature

Figure 12. Unprotected loss of heat sink in ABR reactor and 1.8\$ maximum iFAST worth. 


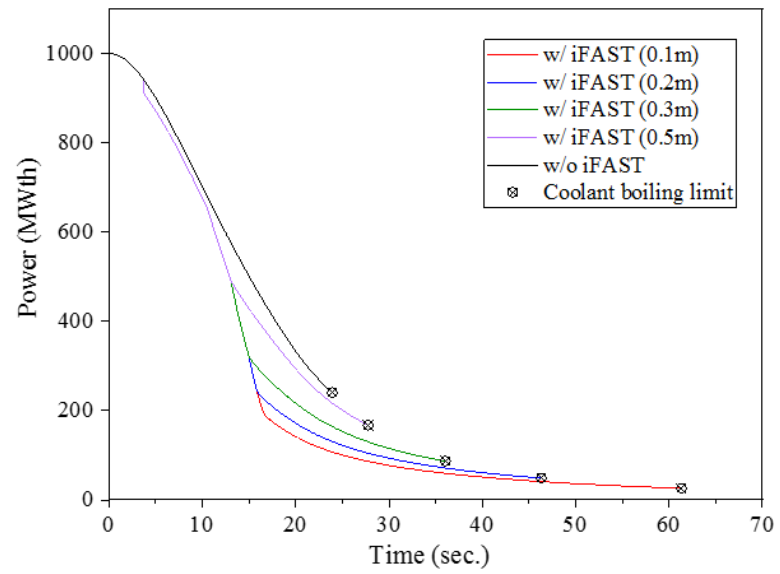

(a) Core power

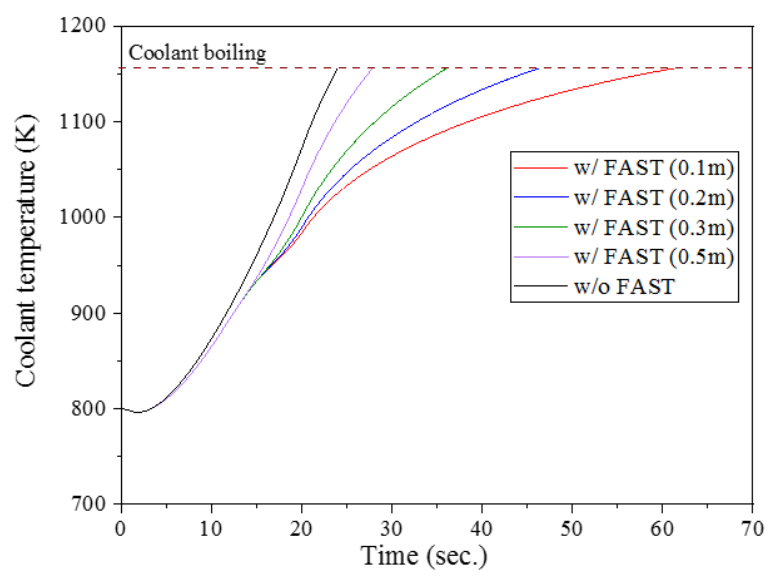

(c) Maximum coolant temperature

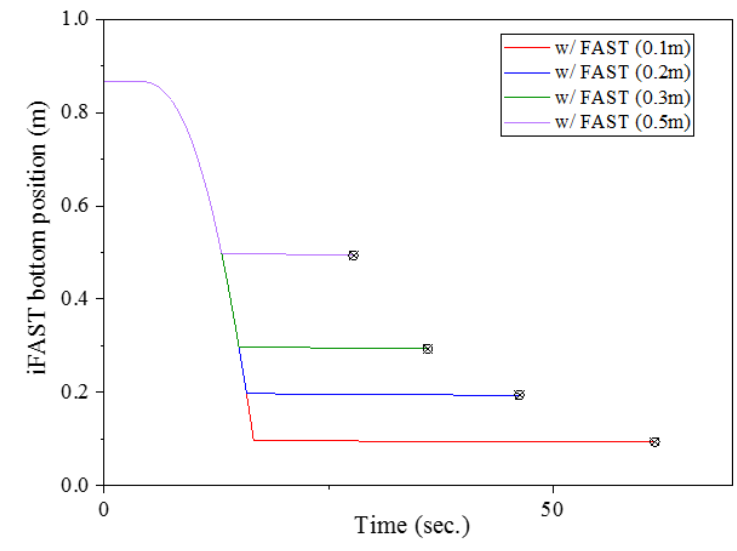

(b) Movement of the absorber module

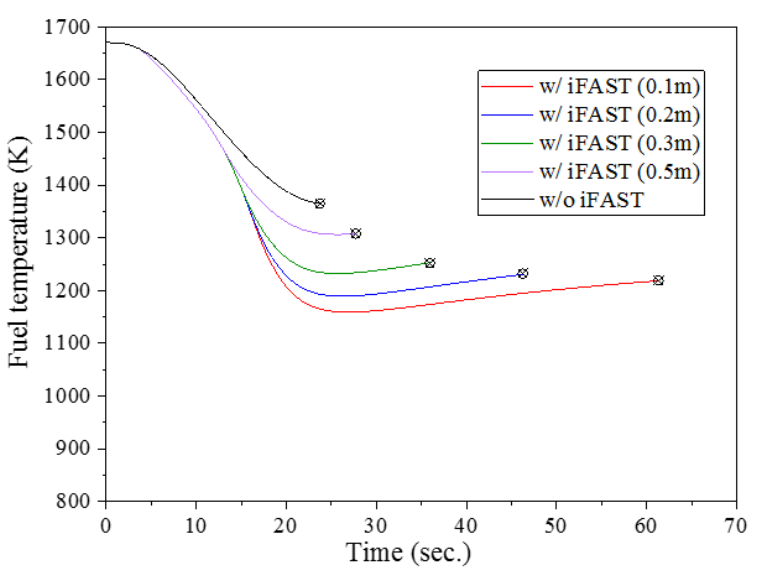

(d) Maximum fuel temperature

Figure 13. Unprotected loss of heat sink in ABR reactor and $1 \$$ maximum iFAST worth.

\section{Conclusions}

Improved FAST device (iFAST) design is proposed. In iFAST, an insertion limit is added based on an optimized insertion region of the absorber module. This is an effective solution to the power oscillation problem that was previously reported for certain ATWS events, especially the UTOP. The paper demonstrates the effectiveness of iFAST in protecting the oxide SFR core from damage during ATWS. Practically, we performed sensitivity analysis on the insertion limit and tested $1.8 \$$ and $1 \$$ maximum worth for the iFAST device. Numerical simulations of ULOF, UTOP, and ULOHS were carried out for the $1000 \mathrm{MW}_{\text {th }}$ advanced burner reactor (ABR), which is an oxide-loaded SFR. The movement of the absorber module is fully passive due to the variation of coolant temperature, which demonstrates the uniqueness of the iFAST device as it directly affects the CTC. This study shows that optimizing the insertion limit and the maximum worth of the device is very important to guarantee reactor safety during severe ATWS events. Particularly, they must be optimized to deny any continuous refloating of the absorber module, even in a severe UTOP case. The oscillation of power during a severe UTOP $(1 \$ / 50 \mathrm{~s})$ is removed by utilizing a $0.2 \mathrm{~m}$ insertion limit and $1 \$$ maximum worth of iFAST. Such values of worth and insertion limits were successful for ULOF. However, the maximum coolant temperature reached boiling temperature for ULOHS. Nevertheless, the iFAST device with a $0.2 \mathrm{~m}$, or deeper, insertion limit and $1.8 \$$ maximum showed promising potentials in protecting the ABR core at EOL during ULOF, ULOHS, and 0.4\$/50 s UTOP. 
Author Contributions: Investigation and analysis, A.A.E.A.; writing-original draft preparation, A.A.E.A.; writing—review and editing, A.A.E.A.; visualization, A.A.E.A.; resources, A.A.E.A.; data curation, A.A.E.A.; formal analysis, C.K., software, C.K.; supervision; Y.K. All authors have read and agreed to the published version of the manuscript.

Funding: The National Research Foundation of Korea (NRF) Grant funded by the Korean Government (MSIP) (NRF-2016R1A5A1013919) supported this work.

Conflicts of Interest: The authors declare no conflict of interest.

\section{References}

1. Ichimiya, M.; Mizuno, T.; Kotake, S. A next generation sodium-cooled fast reactor concept and its R\&D program. Nucl. Eng. Technol. 2007, 39, 171

2. Aoto, K.; Dufour, P.; Hongyi, Y.; Glatz, J.P.; Kim, Y.I.; Ashurko, Y.; Hill, R.; Uto, N. A summary of sodium-cooled fast reactor development. Prog. Nucl. Energy 2014, 77, 247-265. [CrossRef]

3. Hartanto, D.; Kim, C.; Kim, Y. An optimization study on the excess reactivity in a linear breed-and-burn fast reactor (B\&BR). Ann. Nucl. Energy 2016, 94, 62-71.

4. Kim, C.; Jang, S.; Kim, Y. FAST (floating absorber for safety at transient) for the improved safety of sodium-cooled burner fast reactors. Nucl. Eng. Technol. 2020, 53, 1747-1755. [CrossRef]

5. Kim, C.; Kim, Y. Potential of FAST (floating absorber for safety at transient) as a solution for positive coolant temperature coefficient in sodium-cooled FAST reactors. Ann. Nucl. Energy 2020, 137, 107048. [CrossRef]

6. Kwon, Y.M.; Jeong, K.S.; Lee, Y.B.; Chang, W.P.; Hahn, D. An Effect of Gas Expansion Module on the Inherent Safety of the Korea Advanced Liquid Metal Reactor. In Proceedings of the 2000 Autumn Meeting of the KNS, Taejon, Korea, 26-27 October 2000.

7. Qvist, S.; Greenspan, E. An autonomous reactivity control system for improved fast reactor safety. Prog. Nucl. Energy 2014, 77, 32-47. [CrossRef]

8. Cahalan, J.; Fanning, T.; Farmer, M.; Grandy, C.; Jin, E.; Kim, T.; Kellogg, R.; Krajtl, L.; Lomperski, S.; Moisseytsev, A.; et al. Advanced Burner Reactor 1000MWth Reference Concept; Argonne National Lab. (ANL): Argonne, IL, USA, 2000.

9. Chang, Y.I.; Finck, P.J.; Grandy, C.; Cahalan, J.; Deitrich, L.; Dunn, F.; Fallin, D.; Farmer, M.; Fanning, T.; Kim, T.; et al. Advanced Burner Test Reactor Preconceptual Design Report; Argonne National Lab. (ANL): Argonne, IL, USA, 2008.

10. Khalil, M.F.; Kassab, S.Z.; Adam, I.G.; Samaha, M. Laminar flow in concentric annulus with a moving core. In Proceedings of the Twelfth International Water Technology Conference, Alexandria, Egypt, 27-30 March 2008. 